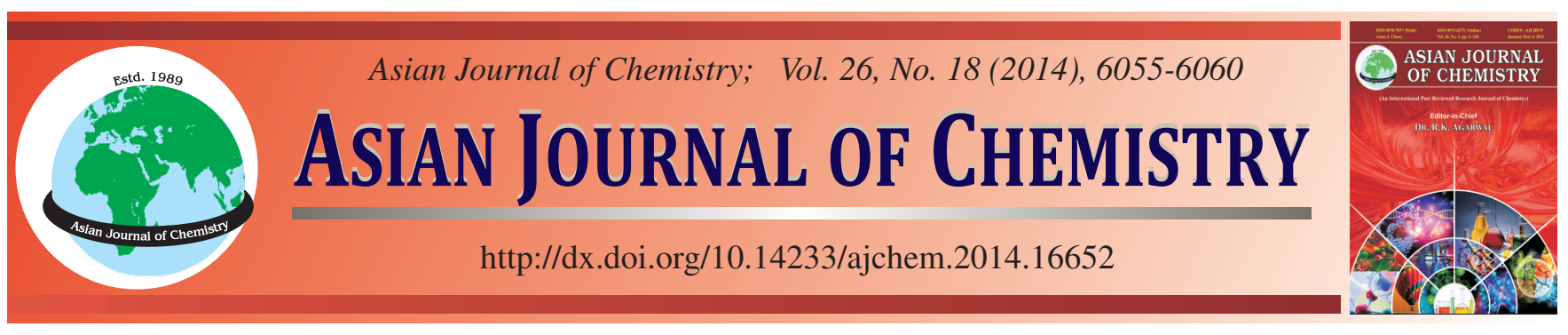

\title{
Preparation and Characterization of Poly Metal Complexes Derived from 5,5'-Methylenebis(2-Hydroxy Benzaldehyde) and 6,6'-Methylenebis(2-hydroxy naphthaldehyde) with Hydrazine and 4-Amino Phenyl Ether
}

\author{
AmbreEn ShaH ${ }^{1, *}$, M.Y. Khuhawar ${ }^{1}$ and Asif Ali ShaH $^{2}$
}

${ }^{1}$ M.A. Kazi Institute of Chemistry, University of Sindh, Jamshoro, Sindh, Pakistan

${ }^{2}$ Mehran University Institute of Science and Technology Development, Jamshoro, Pakistan

*Corresponding author: E-mail: anashba_shah@yahoo.com; a_jeelani2002@yahoo.com

\begin{abstract}
Some new Schiff base polymers were prepared by polycondensation of 5,5'-methylenebis(2-hydroxy benzaldehyde) and 6,6'-methylene bis(2hydroxy naphthaldehyde) with 4-aminophenyl ether and hydrazine in acidic media. After polymerization, Schiff base polymers were treated with $\mathrm{Cu}$ and $\mathrm{Ni}$ acetate to prepare poly metal chelates by solution technique. The poly metal chelates were characterized by elemental micro-analysis, IR, UV-visible and spectroscopic techniques. The solutions of poly metal chelates were prepared in THF at $30^{\circ} \mathrm{C}$, to investigate viscometric study by dilute solution viscometry (DSV) method. The intrinsic viscosities of these poly metal complexes were ranged within 0.393-0.5201 dL/g as compared to 0.174-0.249 dL/g for Schiff base polymers in THF. Thermoanalytical studies of poly metal complexes were examined and compared.
\end{abstract}

Keywords: Poly metal chelates, Schiff base, Infrared spectroscopy, Ultraviolet-visible spectroscopy, Viscometry.

\section{INTRODUCTION}

A polymer-metal chelates is composed from man-made polymer as ligand with metal ions by a coordinate bond. Those polymers contain nitrogen, oxygen or sulphur at anchoring sites, are able to form metal complexes with different metals by coordination covalent bonding ${ }^{1-7}$. Different sort of polymer metal complexes formed with a variety of metal ions such as, cross-linked polymers formed by intramolecular or intermolecular bonding. Some copper(II) and nickel(II) metal chelates were reported from 5,5'-methylene bis(salicylaldehyde) with different diamines tetramethylethylenediimine, meso-stilbenediimine, dl-stilbenediimine and 2,6-diiminopyridine ${ }^{8}$.

Tunçel et al. ${ }^{9}$ synthesized and characterized the thermally stable Schiff base polymers from monomers $\left[\left\{\mathrm{M}_{1} ; \mathrm{N}, \mathrm{N}^{\prime}-p-\right.\right.$ phenylene bis(salicylideneimine) and ethylenediamine $\left(\mathrm{M}_{2}\right.$; $\mathrm{N}, \mathrm{N}$ '-p-ethylenebis(salicylideneimine) \}] by the condensation reaction and also prepared their copper(II), cobalt(II) and nickel(II) complexes. These polymers and their metal chelates were characterized by elemental analyses, UV-visible, FT-IR, atomic absorption spectroscopy (AAS), thermogravimetric analyses and magnetic susceptibility measurements. Thermal stability of metal chelates is higher than Schiff base polymer.

Recently, Zolfaghar et al. ${ }^{10}$ prepared two new tetradentate N,N'-di-[5-(4-alkoxyphenyl)azo]-salicylidene-1,2-phenylene diimine ligands (alkoxy = octloxy, decyloxy) and their nickel(II) chelates. The ligands and their nickel complexes have been characterized by all spectroscopic techniques and by using a polarizing microscope equipped with a heating and cooling stage. None of the free ligands exhibited liquid-crystalline behavior except the copper chelates.

In the present work, the newer polymers were formed by polycondensation of 5, 5'-methylene bis(2-hydroxybenzaldehyde) and 6,6'-methylene bis(2-hydroxy naphthaldehyde) with hydrazine as well as 4-amino phenyl ether. These polymers formed metal chelates with copper and nickel metal ions. These metal complexes were characterized by CHN analysis, FT-IR and UV/visible spectroscopy. The viscometric parameters (intrinsic viscosity and absolute viscosity) of polymeric solution in THF were obtained by extrapolation with different temperatures and concentrations and based on DSV method.

\section{EXPERIMENTAL}

2-Hydroxy(naphthaldehyde), hydrazine, 4-amino phenyl ether, glacial acetic acid, sulphuric acid (98\%), chloroform, $n$-hexane, $\mathrm{NH}_{4} \mathrm{OH}$, dimethyl acetamide (DMAc), dimethylformamide (DMSO), tetrahydrofuran (THF), acetone, methanol, $\mathrm{Cu}(\mathrm{II})$ acetate and $\mathrm{Ni}(\mathrm{II})$ acetate obtained from (Fluka, Switerzerland) were used. Pure nitrogen obtained from British Oxygen Company (BOC), Karachi, was used. 
The elemental micro-analyses were carried out by a Devon elemental microanalyzer (UK). Infrared spectra were recorded on a Nicolet Avatar 330 FTIR (Thermo Nicolet Electron Corporation, USA) with attenuated total reflectance (ATR) accessory (Smart partner) within $4000-600 \mathrm{~cm}^{-1}$. Spectrophotometric studies were carried out in dimethyl formamide (DMF) and tetrahydrofuran (THF) on a double beam Hitachi 220 spectrophotometer (Tokyo, Japan), with dual $1 \mathrm{~cm}$ silica cuvettes within 185-700 nm.

Thermogravimetry (TG) and differential thermal analysis (DTA) were recorded on a Shimadzu TG 30 thermal analyzer from room temperature to $600{ }^{\circ} \mathrm{C}$ with a nitrogen flow rate of $50 \mathrm{~mL} / \mathrm{min}$. The known samples of copper and nickel complexes $(10 \mathrm{mg})$ were placed in platinum sample holder and $\alpha$ alumina was used as reference. The viscosity measurements of dialdehyde (MBC) and their polythioamides were noted within temperatures $283-323 \mathrm{~K}$ with interval of $10 \mathrm{~K}$ by using a Technico ASTM 445 suspended level viscometer. Each time $15 \mathrm{~mL}$ of solution was taken and an average flow time of at least three readings was taken. The flow time of solvent under the same condition was also noted. A Gallenkamp viscometer bath was used to control the temperature.

Preparation of polymers: The preparation of 5,5'methylene bis(2-hydroxy benzaldehyde) as well as their polymers are reported, and the procedure for 6,6'-methylene bis(2-hydroxy naphthaldehyde) was given below: To 6,6'methylene bis(2-hydroxy naphthaldehyde) (1.78 g) dissolved in DMSO $(50 \mathrm{~mL})$ was added hydrazine $(0.16 \mathrm{~mL})$ or 4 -amino phenyl ether $(1.002 \mathrm{~g})$ dissolved in THF $(5 \mathrm{~mL})$ and acetic acid $(2 \mathrm{~mL})$. The reaction mixture was refluxed for $24 \mathrm{~h}$ with constant stirring, the content was concentrated to about half of the volume and the mixture was poured to ethanol $(50 \mathrm{~mL})$. The coloured precipitates obtained, were filtered and dried in oven. Finally, recrystallized the crude precipitates in acetone and $n$-hexane.

Preparation of of poly metal complexes: Polymeric Schiff metal chelates were prepared by a solution technique. A typical procedure for the preparation is as follows ${ }^{11}$ with some modification:

$2 \mathrm{mmol}$ of polymer was dissolved in $(100 \mathrm{~mL})$ of THF and the $\mathrm{pH}$ of solution was adjusted to 7 with dilute $\mathrm{NH}_{4} \mathrm{OH}$. An aqueous solution of $\mathrm{Cu}(\mathrm{II})$ acetate $(5 \mathrm{mmol})$ was added drop wise to the Schiff base polymeric solution with constant stirring in nitrogen atmosphere. The mixture was then digested at $80-85^{\circ} \mathrm{C}$ for $14 \mathrm{~h}$ and kept overnight at room temperature with continuous stirring. The reaction mixture was poured in chilled water. The precipitates of metal chelates formed, was filtered, washed with hot distilled water and recrystallized from ethanol. This crude product was dried at $100{ }^{\circ} \mathrm{C}$. The similar procedure was adopted for the preparation of $\mathrm{Ni}(\mathrm{II})$ chelates.

Poly[6,6'-methylene bis(2-hydroxy naphthaldehyde)azine] Cu complex [PMBHNH Cu(II)]: FTIR: 3046, 3028, 2994, 2856, 1632, 1618, 1562, 1494, 1377, 1356, 1280, $1208,1164,978,934,855,815,767,720 \mathrm{~cm}^{-1}$. Analysis of $\left(\mathrm{C}_{24} \mathrm{H}_{14} \mathrm{~N}_{2} \mathrm{O}_{2} . \mathrm{Cu}\right)_{\mathrm{n}}$, calculated (\%): C, 51.27; H, 2.49; N, 4.98. Found (\%): C, 51.15; H, 2.51; N, 4.79.

Poly[ 6,6'-methylene bis(2-hydroxy naphthaldehyde)4-imino phenyl ether] $\mathrm{Cu}$ complex [PMBHNIPE $\mathrm{Cu}(\mathrm{II})]$ : FTIR: 3024, 3010, 2977, 1619, 1590, 1445, 1382, 1281, 1171,
$1030,908,917,856,759,707 \mathrm{~cm}^{-1}$. Analysis of $\left(\mathrm{C}_{36} \mathrm{H}_{22} \mathrm{~N}_{2} \mathrm{O}_{3} \cdot \mathrm{Cu}\right)_{\mathrm{n}}$, calculated (\%): C, 59.2; H, 3.01; N, 3.83; S. Found (\%): C, 59.08; H, 2.99; N, 3.74.

Poly [6,6'-methylene bis(2-hydroxy naphthaldehyde)azine] Ni complex [PMBHNH Ni(II)]: FTIR: 3020, 3006, 2900, 2830, 1620, 1550, 1480, 1406, 1395, 1220, 1145, 1020, 900, 855, 760, $714 \mathrm{~cm}^{-1}$. Analysis of $\left(\mathrm{C}_{24} \mathrm{H}_{14} \mathrm{~N}_{2} \mathrm{O}_{2} . \mathrm{Ni}\right)_{\mathrm{n}}$, calculated (\%): C, 48.02; H, 2.33; N, 5.05. Found (\%): C, 47.97; H, 2.35; N, 4.93.

Poly[ 6,6'-methylene bis(2-hydroxy naphthaldehyde)4-imino phenyl ether] Ni complex [PMBHNIPE Ni(II)]: FTIR: 3067, 3033, 2979, 2880, 1635, 1598, 1583, 1460, 1460, $1123,1048,924,880,834,766,700 \mathrm{~cm}^{-1}$. Analysis of $\left(\mathrm{C}_{36} \mathrm{H}_{22} \mathrm{~N}_{2} \mathrm{O}_{3} . \mathrm{Ni}\right)_{\mathrm{n}}$, calculated (\%): C, 56.2; H, 2.86; N, 3.64. Found (\%): C, 56.08; H, 2.89; N, 3.59 .

\section{RESULTS AND DISCUSSION}

Synthesis: Monomer was prepared as reported method, which is a general procedure for the preparation of 5,5'methylene bis(2-hydroxy benzaldehyde), 6,6'-methylene bis(2hydroxy naphthaldehyde) and 5,5'-methylene bis(2-hydroxy acetophenone $)^{12,13}$. The prepared monomer was further used to prepare new Schiff polymers by polycondensation with hydrazine and 4-aminophenylether. Each time a solid product was obtained. Structural formulae of Schiff base polymers are given in (Fig. 1). These polymers were further reacted with $\mathrm{Cu}$ (II) and $\mathrm{Ni}$ (II) metal solution, to prepare poly metal chelates. After synthesis, poly metal chelates confirmed by elemental analysis (Table-1) and spectroscopic techniques.

The effects of reaction conditions were examined for the syntheses of poly metal complexes were examined. Heating time of reaction mixture was varied for $6,14,18$ and $20 \mathrm{~h}$ but maximum yield was obtained at $85^{\circ} \mathrm{C}$ with $14 \mathrm{~h}$ of heating and were selected. Solubility of polymers and its poly metal chelates were insoluble in water but soluble in methanol ethanol, acetone, chloroform, THF and $\mathrm{DMF}^{14}$.
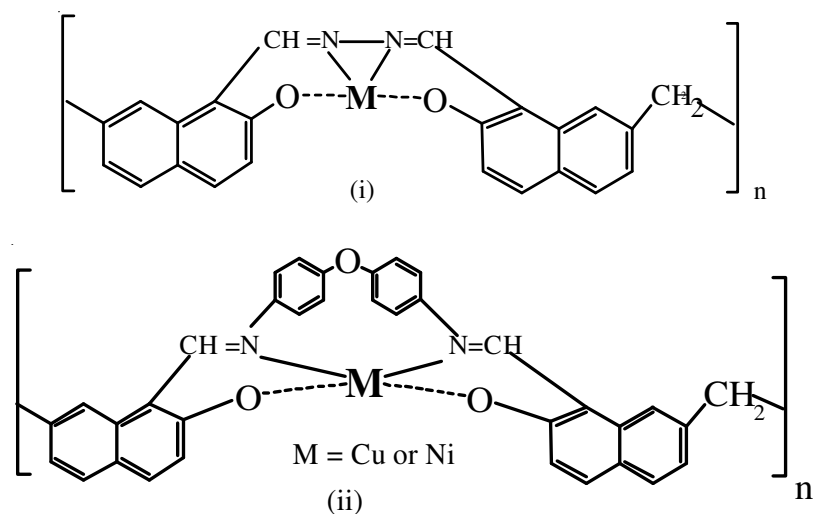

(ii)

Fig. 1. (i) Structure diagrams of poly Schiff metal chelates of poly 6,6'methylene bis(2-hydroxy naphthaldehyde) hydrazone and (ii) poly Schiff metal chelates of poly 6,6'-methylene bis(2-hydroxy naphthaldehyde) 4-imino phenyl ether

Spectral studies: IR spectrum of monomer indicated strong bands at aldehyde reacts with diamines then absorption of infrared radiation causes covalent bonds within the molecule to be promoted from one vibrational energy level to high energy level. Copper(II) and nickel(II) metal chelates gave 


\begin{tabular}{|c|c|c|c|c|c|c|c|c|}
\hline \multicolumn{9}{|c|}{ 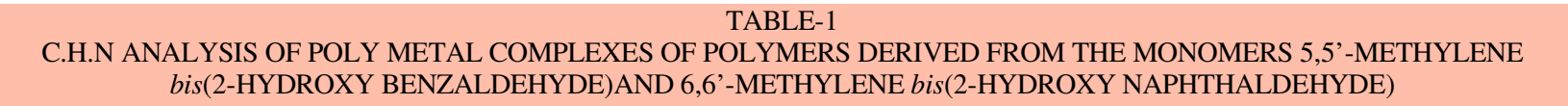 } \\
\hline \multirow{2}{*}{ S.\#: } & \multirow{2}{*}{ Compounds } & \multirow{2}{*}{ m.f. } & \multicolumn{3}{|c|}{$\%$ Calculated } & \multicolumn{3}{|c|}{$\%$ Found } \\
\hline & & & $\mathrm{C}$ & $\mathrm{H}$ & $\mathrm{N}$ & $\mathrm{C}$ & $\mathrm{H}$ & $\mathrm{N}$ \\
\hline 1 & [PMBHBHCu(II)] & $\left(\mathrm{C}_{15} \mathrm{H}_{10} \mathrm{~N}_{2} \mathrm{O}_{2} \mathrm{Cu}\right)_{\mathrm{n}}$ & 40.03 & 2.23 & 6.22 & 40.01 & 2.31 & 6.10 \\
\hline 2 & [PMBHBIPECu(II)] & $\left(\mathrm{C}_{27} \mathrm{H}_{18} \mathrm{~N}_{2} \mathrm{O}_{2} \cdot \mathrm{Cu}\right)_{\mathrm{n}}$ & 52.45 & 2.91 & 4.53 & 52.22 & 2.67 & 4.28 \\
\hline 3 & [PMBHBHNi(II)] & $\left(\mathrm{C}_{15} \mathrm{H}_{10} \mathrm{~N}_{2} \mathrm{O}_{2} \cdot \mathrm{Ni}\right)_{\mathrm{n}}$ & 36.10 & 2.05 & 5.74 & 35.89 & 2.10 & 5.52 \\
\hline 4 & [PMBHBIPENi(II)] & $\left(\mathrm{C}_{27} \mathrm{H}_{18} \mathrm{~N}_{2} \mathrm{O}_{2} \cdot \mathrm{Ni}\right)_{\mathrm{n}}$ & 49.41 & 2.74 & 4.27 & 49.24 & 2.62 & 4.16 \\
\hline 5 & [PMBHNHCu(II)] & $\left(\mathrm{C}_{24} \mathrm{H}_{14} \mathrm{~N}_{2} \mathrm{O}_{2} \cdot \mathrm{Cu}\right)_{\mathrm{n}}$ & 51.27 & 2.49 & 4.98 & 51.15 & 2.51 & 4.79 \\
\hline 6 & [PMBHNIPECu(II)] & $\left(\mathrm{C}_{36} \mathrm{H}_{22} \mathrm{~N}_{2} \mathrm{O}_{3} \cdot \mathrm{Cu}\right)_{\mathrm{n}}$ & 59.2 & 3.01 & 3.83 & 59.08 & 2.99 & 3.74 \\
\hline 7 & [PMBHNHNi(II)] & $\left(\mathrm{C}_{24} \mathrm{H}_{14} \mathrm{~N}_{2} \mathrm{O}_{2} \cdot \mathrm{Ni}\right)_{\mathrm{n}}$ & 48.02 & 2.33 & 5.05 & 47.97 & 2.35 & 4.93 \\
\hline 8 & [PMBHNIPENi(II)] & $\left(\mathrm{C}_{36} \mathrm{H}_{22} \mathrm{~N}_{2} \mathrm{O}_{3} \cdot \mathrm{Ni}\right)_{\mathrm{n}}$ & 56.20 & 2.86 & 3.64 & 56.0 & 2.89 & 3.59 \\
\hline
\end{tabular}

weak absorption band at $3082-3016 \mathrm{~cm}^{-1}$ due to $\mathrm{C}-\mathrm{H}$ aromatic stretching. Infrared spectrum of poly metal chelates gave rise a characterized peak around $1648-1615 \mathrm{~cm}^{-1}$ due to $\mathrm{v}(\mathrm{C}=\mathrm{N})$ vibration frequencies. The imine peak $(-\mathrm{HC}=\mathrm{N}$ - group $)$ in metal complexes were showed red shifts below $12-20 \mathrm{~cm}^{-1}$ compared to polymers, indicating coordination of the imine nitrogen to the metal ions. These poly metal chelates indicated a few bands within $1603-1580 \mathrm{~cm}^{-1}$ due to aromatic ring and $\mathrm{C}=\mathrm{C}$ vibration. All gave two to three bands within $1578-1395 \mathrm{~cm}^{-1}$ due to aliphatic and aromatic ring and $\mathrm{v}(\mathrm{C}=\mathrm{C})$ vibration. Another peak of N-N vibration was only found in poly metal complexes of hydrazine around 1440-1340 $\mathrm{cm}^{-1}$. The $\mathrm{C}-\mathrm{O}-\mathrm{Cu}$ band frequency in metal complexes appeared $1281 \mathrm{~cm}^{-1}$ as strong band, indicating involvement of phenolate oxygen atom in the coordination $^{15}$. These frequencies also observed in $\mathrm{Cu}$ complexes [Fig. 2 (a \& b)].

The electronic spectra of newly synthesized poly metal chelates were carried out in THF. As the polymers indicted almost three absorption bands due to $\pi-\pi^{*}$ transition in the benzenoid rings, $\pi-\pi^{*}$ conjugated carbonyl groups and $\mathrm{C}=\mathrm{N}$ chromophic groups of compounds. The metal chelates indicated three or four bands [Fig. 3 (a \& b)] and the observation of a new band or the shift in the position of the band as compared to Schiff base polymers might be attributed to metal ions incorporated in the metal chelates. The initial absorption

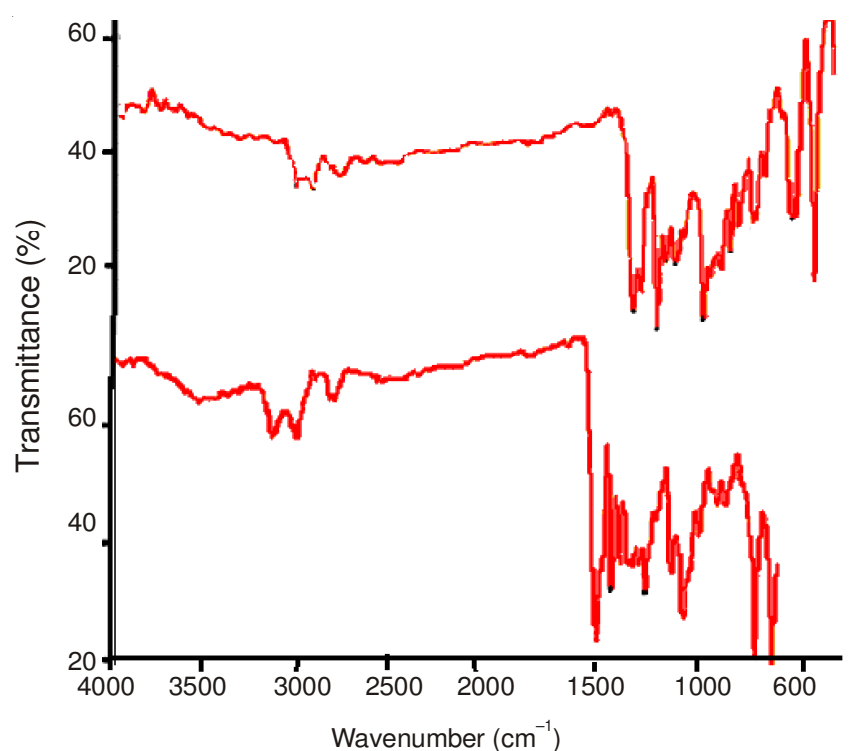

Fig. 2. (a) Infrared spectrum for poly metal chelate (PMBHBHCu) and (PMBHNHCu)

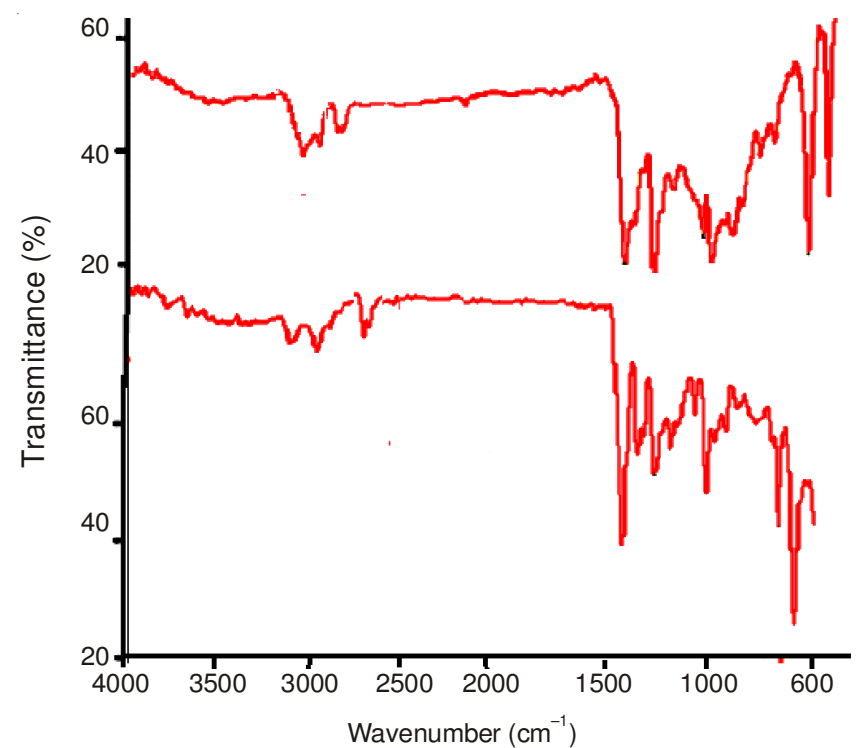

Fig. 2 (b) Infrared spectrum for poly metal chelate (PMBHBIPECu) and (PMBHNIPECu)

band appeared due to $\pi-\pi^{*}$ transition in the benzoid and phenyl system and a hypsochromic shift of 8-12 $\mathrm{nm}$ also appeared in THF solvent as compare to acetone.

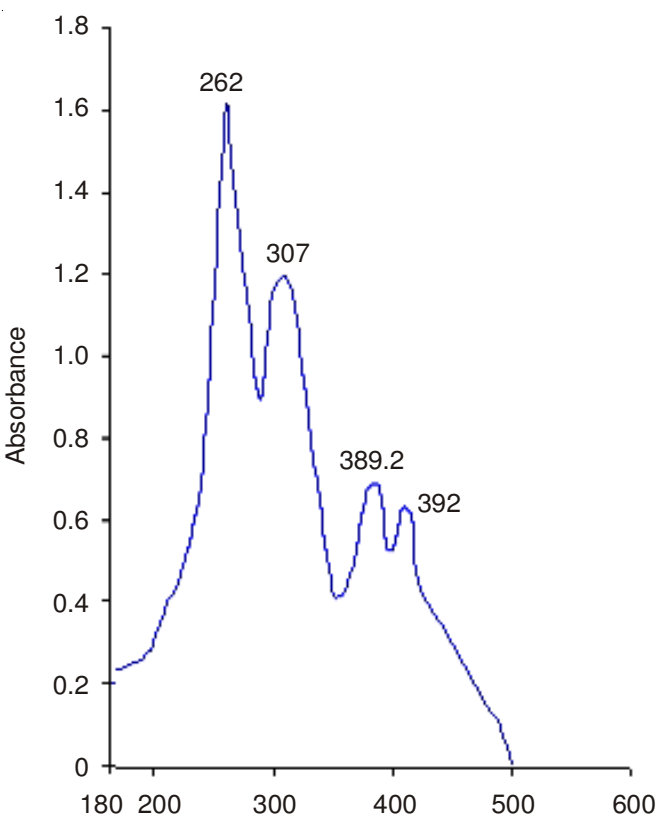

Wavelength (nm)

Fig. 3. (a) UV/visible spectrum for poly metal chelate (PMBHBHCu) 


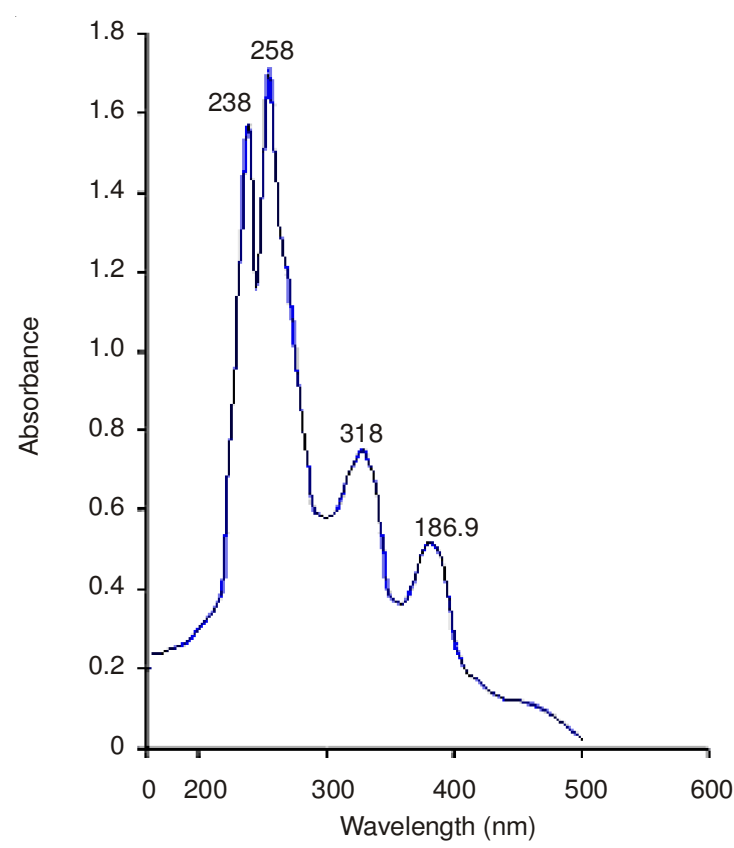

Fig. 3. (b) UV/visible spectrum for poly metal chelate (PMBHNIPECu)

The new band with strong intensity for all metal complexes were observed between 290-330 nm, which indicated bathochromic shift, this assigned for $\pi-\pi^{*}$ transition involving the ligand $\pi$-orbital near carbonyl oxyge ${ }^{13}$. The copper chelates indicated a shoulder band between 340-400 nm which might be due to a charge transfer band but in nickel metal chelates these shoulder bands were obtained after 410-440 $\mathrm{nm}$ with higher absorbance. Therefore it was concluded that the nickel chelates were more planar than copper chelates ${ }^{16}$.

Thermal properties: The thermal stability by thermogravimatry (TG) and differential thermal analysis (DTA) of these newly prepared poly metal chelates were recorded from room temperature to $600{ }^{\circ} \mathrm{C}$ with a heating rate $15{ }^{\circ} \mathrm{C} / \mathrm{min}$ and nitrogen flow rate $50 \mathrm{~mL} / \mathrm{min}$.

The weight loss for copper and nickel chelates of (PMBHBH) started from 370 and $380{ }^{\circ} \mathrm{C}$ upto $480{ }^{\circ} \mathrm{C}$, then the loss in weight followed till $700{ }^{\circ} \mathrm{C}$ with total loss of 80 and $78 \%$. The TGA for copper and nickel complexes of (PMBHBIPE) showed many variations from $500-565^{\circ} \mathrm{C}$ with $64 \%$ weight loss but its nickel complexes gave three clear humps $220-280,390-430$ and $342-525^{\circ} \mathrm{C}$ with $69 \%$ weight loss, correspondingly [Fig. 4 (a \& b)].

The thermograph for copper and nickel complexes of (PMBHNH) observed maximum weight loss temperature at 385 and $410^{\circ} \mathrm{C}$ with 78 and $73 \%$ till $700{ }^{\circ} \mathrm{C}$. The copper and nickel complexes of (PMBHNIPE) indicated maximum weight loss temperature at 430 and $408{ }^{\circ} \mathrm{C}$ with 70 and $68 \%$ till $700{ }^{\circ} \mathrm{C}$.

According to thermogravimetric analysis, nickel chelates were more thermally stable than corresponding copper chelates and loss in weight in nickel complexes was almost quantitative (70- $75 \%$ ) up to $410{ }^{\circ} \mathrm{C}$, but copper chelates were more volatile in nature as followed by nickel chelates. This work also agreed with reported work ${ }^{17}$.

Viscosity studies: The viscosity measurements of dialdehyde MBC and newly synthesized formed were recorded

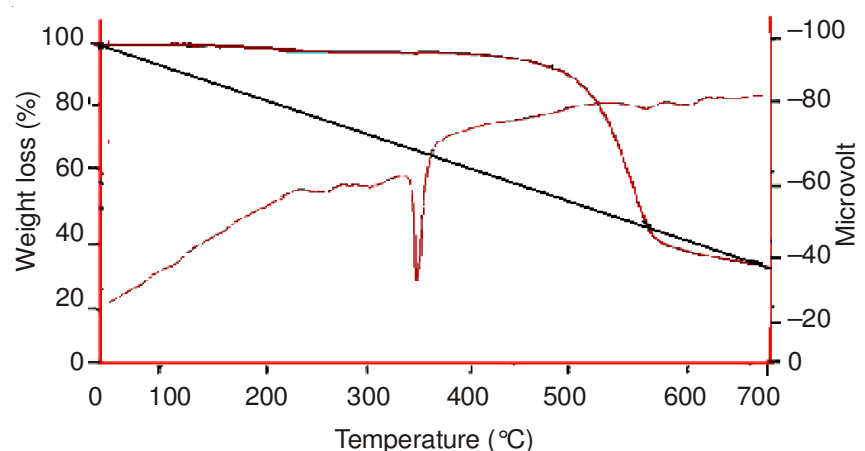

Fig. 4. (a) Thermogravimetric Spectrum for poly metal chelate (PMBHBIPECu)

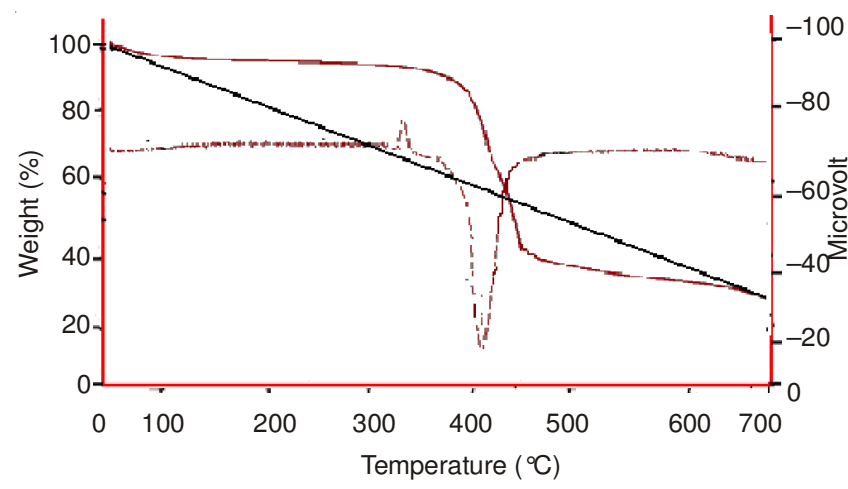

Fig. 4. (b) TG/DTA thermogram for poly metal chelate (PMBHNIPENi)

within $283-323 \mathrm{~K}$ with concentration within $0.02-0.08 \mathrm{~g} / \mathrm{dL}$ in THF. The relationship between the reduced viscosity $\left(\eta_{\text {red }}\right)$ and concentration was observed linear for all poly metal complexes the compounds and an increase in reduced viscosity was observed with an increase in concentration and decrease in temperature (Fig: 5). The intrinsic viscosity for poly metal complexes of bis(2-hydroxy benzaldehyde)/bis(2-hydroxy naphthaldehyde) was calculated from Huggins's equation. According to equation, when a graph is plotted between reduced viscosity versus concentrations, then intercept gave the intrinsic viscosity of polymeric solution. Intrinsic viscosity increased with increase in molecular weight of metal chelate as (PMBHNHNi) $(1.173 \mathrm{dL} / \mathrm{g})$ which was higher than (PMB$\mathrm{HBHNi}$ ) as well as (PMBHNHCu) complexes intrinsic viscosity decreased on high temperature. The values are summarized in (Table-2). The poly metal chelates indicated increasing intrinsic viscosity in the series $(\mathrm{PMBHBHCu})<(\mathrm{PMBHBHNi})$
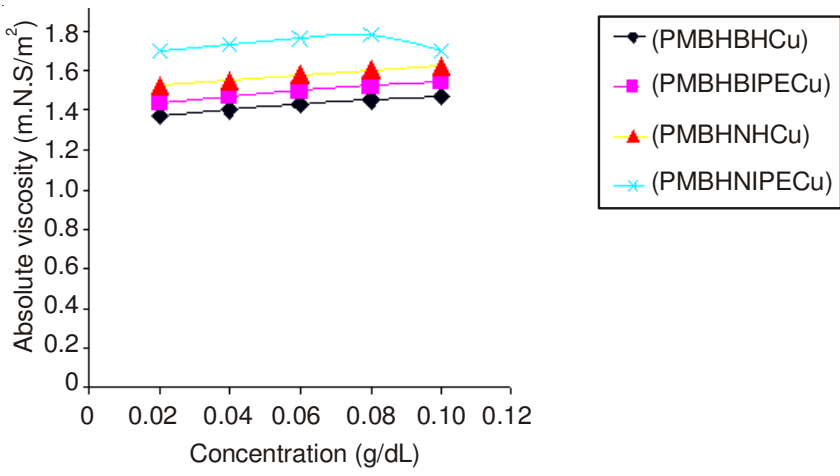

Fig. 5. Absolute viscosity vs. concentration for different copper complexes (m.N.S $/ \mathrm{m}^{2}$ ). 
$<(\mathrm{PMBHBIPECu})<(\mathrm{PMBHNHCu})<(\mathrm{PMBHNHNi})<$ $($ PMBHBIPENi $)<($ PMBHNIPECu $)<($ PMBHNIPENi $)$. The poly chelate (PMBHBIPENi) had highest intrinsic viscosity in the series and might be due to considered have highest molecular mass because intrinsic viscosity depend upon molecular mass of the compound. Similar trend of intrinsic viscosities were also obtained in reported data ${ }^{18,19}$ in THF, which gave intrinsic viscosities within $0.019-0.241 \mathrm{~g} / \mathrm{dL}$ in different solutions. The nature of the solvent has the predominant effect on the values of the Huggins viscometric constant in polymeric solutions. The poly metal complex (PMBHBIPE) $\mathrm{Cu}$ has less power of solvation in solvent than (PMBHNH)Cu because of the high aromatic character of phenyl rings in poly chelate of 4-imino phenyl ether (Table-3).

The values of absolute viscosity of poly metal chelates increased with increase in concentration and decreased with increase in temperature (Table-4). The values of absolute viscosities for poly metal chelates ranged within 1.27-2.06 $\mathrm{mNS} / \mathrm{m}^{2}$ in different concentrations of polymeric solutions.

The thermodynamic parameters of polymeric solution have characteristics behaviors which gave information about the structure and orientation of polymer molecules in the dilute solution. The energy of activation of viscous flow was calculated from the viscosity of a system using eqn. 1, as following:

$$
\Delta \mathrm{G}=2.303 \mathrm{RT} \log \left(\eta_{\mathrm{abs}} / 10^{-3}\right)
$$

where $\mathrm{R}$ is gas constant and $\mathrm{T}$ is absolute temperature. $\mathrm{A}$ straight line was obtained by potting $\log \eta_{\text {abs }}$ versus $1 / \mathrm{T}$. The energy of activation $\left(\Delta \mathrm{G}_{\mathrm{v}}\right)$ of (PMBHNIPENi) was gradually raised with increase in concentrations of dilute solution because molecules have weaker association with each other and easily overcome during flow of solution. The values of $\Delta \mathrm{G}_{\mathrm{v}}$ for $\mathrm{MBC}$ were lower at different temperature about 11.989-14.1287 kJ $\mathrm{mol}^{-1}$ as compared to the poly metal complexes. The results of metal chelates at different temperature and concentration are listed in (Table-5).

when a graph was plotted between $\log \eta$ versus $1 / \mathrm{T}$, then a straight line was obtained. The values of heat of activation of flow $(\Delta \mathrm{Hv})$ were calculated from the slope (Slope $\times \mathrm{R})$. As the molecular mass was increased, the results of $\Delta \mathrm{H}_{\mathrm{v}}$ became lower because more energy was required to over came the flow of polymeric solvents (Table-6). The values of $\Delta \mathrm{H}_{\mathrm{v}}$ indicated the process of degradation of structure and orientation of macromolecule during the flow process. These newly prepared poly metal complexes indicated negative values so they showed the process of uncoiling and orientation of macromolecules occurred during flow process The entropy of activation of viscous flow $\left(\Delta S_{v}\right)$ was calculated from equation:

$$
\Delta \mathrm{G}_{\mathrm{v}}=\Delta \mathrm{H}_{\mathrm{v}}-\mathrm{T} \Delta \mathrm{S}_{\mathrm{v}}
$$

\begin{tabular}{|c|c|c|c|c|c|c|}
\hline \multirow{3}{*}{ S.No } & \multicolumn{5}{|c|}{$\begin{array}{c}\text { TABLE-2 } \\
\text { INTRINSIC VISCOSITY OF POLY METAL CHELATES AT DIFFERENT TEMPERATURES }\end{array}$} & \\
\hline & \multirow{2}{*}{ Compound } & \multicolumn{5}{|c|}{ Temperature (K) } \\
\hline & & 283 & 293 & 303 & 313 & 323 \\
\hline 1 & (PMBHBHCu) & 0.65 & 0.57 & 0.49 & 0.41 & 0.33 \\
\hline 2 & (PMBHBHNi) & 0.76 & 0.685 & 0.66 & 0.635 & 0.61 \\
\hline 3 & (PMBHBIPECu) & 0.91 & 0.88 & 0.86 & 0.83 & 0.81 \\
\hline 4 & (PMBHNHCu) & 1.05 & 0.97 & 0.82 & 0.81 & 0.73 \\
\hline 5 & (PMBHNHNi) & 1.17 & 1.10 & 1.03 & 0.96 & 0.89 \\
\hline 6 & (PMBHBIPENi) & 1.11 & 1.085 & 1.06 & 1.035 & 1.01 \\
\hline 7 & (PMBHNIPECu) & 1.31 & 1.285 & 1.26 & 1.235 & 1.21 \\
\hline 8 & (PMBHNIPENi) & 1.45 & 1.37 & 1.29 & 1.21 & 1.13 \\
\hline
\end{tabular}

TABLE-3

HUGGIN'S CONSTANT $\mathrm{K}_{\mathrm{H}}$ OF POLY METAL CHELATES AT DIFFERENT CONCENTRATIONS

\begin{tabular}{lllccc}
\hline \multirow{2}{*}{ Compound } & \multicolumn{5}{c}{ Temperature $(\mathrm{K})$} \\
\cline { 2 - 6 } & 283 & 293 & 303 & 313 & 323 \\
\hline (PMBHBHCu) & 0.85 & 0.82 & 0.79 & 0.77 & 0.76 \\
(PMBHBHNi) & 0.86 & 0.84 & 0.81 & 0.78 & 0.78 \\
(PMBHBIPECu) & 0.92 & 0.89 & 0.86 & 0.83 & 0.83 \\
(PMBHNHCu) & 0.99 & 0.97 & 0.94 & 0.91 & 0.91 \\
(PMBHNHNi) & 1.05 & 1.03 & 1.00 & 0.98 & 0.97 \\
(PMBHBIPENi) & 1.12 & 1.09 & 1.06 & 1.03 & 1.03 \\
(PMBHNIPECu) & 1.18 & 1.15 & 1.12 & 1.09 & 1.09 \\
(PMBHNIPENi) & 1.26 & 1.23 & 1.20 & 1.17 & 1.17 \\
\hline
\end{tabular}

TABLE-4

ABSOLUTE VISCOSITY $v / s$ CONCENTRATION FOR DIFFERENT COPPER CHELATES $\left(\mathrm{m} . \mathrm{N} . \mathrm{S} / \mathrm{m}^{2}\right)$

\begin{tabular}{ccccc}
\hline \multirow{2}{*}{ Concentration $(\mathrm{g} / \mathrm{dL})$} & \multicolumn{4}{c}{ Temperature $(283 \mathrm{~K})$} \\
\cline { 2 - 5 } & $(\mathrm{PMBHBHCu})$ & $($ PMBHBIPECu $)$ & $($ PMBHNHCu $)$ & $($ PMBHNIPECu $)$ \\
\hline 0.02 & 1.37 & 1.44 & 1.52 & 1.70 \\
0.04 & 1.40 & 1.47 & 1.55 & 1.73 \\
0.06 & 1.43 & 1.50 & 1.60 & 1.76 \\
0.08 & 1.45 & 1.52 & 1.62 & 1.78 \\
0.10 & 1.47 & 1.54 & & 1.70 \\
\hline
\end{tabular}




\begin{tabular}{|c|c|c|c|c|c|c|}
\hline \multirow{2}{*}{ S. No. } & \multicolumn{5}{|c|}{$\begin{array}{c}\text { TABLE-5 } \\
\text { FREE ENERGY ACTIVATION OF VISCOUS FLOW }\left(\Delta \mathrm{G}_{\mathrm{v}}\right) \text { OF POLY METAL } \\
\text { CHELATES AT DIFFERENT CONCENTRATIONS }\left(\mathrm{K} .{\left.\mathrm{J} . \mathrm{mol}^{-2}\right)}^{\text {Th }}\right.\end{array}$} & \\
\hline & Compound & 283 & 293 & 303 & 313 & 323 \\
\hline 1 & (PMBHBHCu) & 13.21 & 13.27 & 13.33 & 13.39 & 13.46 \\
\hline 2 & (PMBHBHNi) & 13.44 & 13.51 & 13.56 & 13.61 & 13.66 \\
\hline 4 & (PMBHNHCu) & 14.44 & 14.51 & 14.56 & 14.61 & 14.66 \\
\hline 5 & (PMBHNHNi) & 14.64 & 14.72 & 14.76 & 14.80 & 14.86 \\
\hline 6 & (PMBHBIPENi) & 13.84 & 13.90 & 13.96 & 14.01 & 14.06 \\
\hline 7 & (PMBHNIPECu) & 14.04 & 14.11 & 14.16 & 14.2 & 14.26 \\
\hline 8 & (PMBHNIPENi) & 14.24 & 14.30 & 14.36 & 14.39 & 14.46 \\
\hline
\end{tabular}

\begin{tabular}{|c|c|c|c|c|c|c|}
\hline \multirow{3}{*}{ S. No. } & \multicolumn{5}{|c|}{$\begin{array}{c}\text { TABLE-6 } \\
\text { ENTHALPY OF ACTIVATION OF VISCOUS FLOW }\left(\Delta \mathrm{H}_{\mathrm{v}}\right) \text { FOR POLY } \\
\text { METAL CHELATES AT DIFFERENT TEMPERATURES }\left(\mathrm{K} . \mathrm{J}^{\left.-\mathrm{mol}^{-2}\right)}\right.\end{array}$} & \\
\hline & \multirow{2}{*}{ Compound } & \multicolumn{5}{|c|}{ Temperature (K) } \\
\hline & & 283 & 293 & 303 & 313 & 323 \\
\hline 1 & (PMBHBHCu) & 11.28 & 11.22 & 11.16 & 11.11 & 11.04 \\
\hline 2 & (PMBHBHNi) & 10.32 & 10.26 & 10.20 & 10.14 & 10.08 \\
\hline 3 & (PMBHBIPECu) & 9.37 & 9.31 & 9.25 & 9.19 & 9.13 \\
\hline 4 & (PMBHNHCu) & 9.11 & 9.05 & 8.99 & 8.93 & 8.87 \\
\hline 5 & (PMBHNHNi) & 8.75 & 8.69 & 8.63 & 8.57 & 8.51 \\
\hline 6 & (PMBHBIPENi) & 8.42 & 8.36 & 8.30 & 8.24 & 8.18 \\
\hline 7 & (PMBHNIPECu) & 7.46 & 7.40 & 7.34 & 7.28 & 7.22 \\
\hline
\end{tabular}

\section{Conclusion}

This research work represents the synthesis of $\mathrm{Cu}$ (II) and $\mathrm{Ni}$ (II) metal chelates from dialdehydes 5,5'-methylenebis(2hydroxy benzaldehyde) and 6,6'-methylenebis(2-hydroxy naphthaldehyde) with hydrazine and 4-aminophenylether by polycondensation and characterized by various spectroscopic techniques. The N-N vibration was only obtained in poly metal chelates of hydrazine between $1440-1340 \mathrm{~cm}^{-1}$. The metal complexes also indicated C-O-M band frequency around 1281 $\mathrm{cm}^{-1}$ as strong band, representing the phenolate oxygen atom, after complexation. The obtained polymeric metal chelates have good thermal stability with loss of $70-75 \%$ up to $600{ }^{\circ} \mathrm{C}$ due to the presence of heavy metal ions than polymer. The viscometric measurements for these metal complexes were discussed. However, the intrinsic viscosities of these polymeric metal chelates ranged within $0.33-1.45 \mathrm{dL} / \mathrm{g}$ with concentration of solvents, at different temperatures. Finally, all thermodynamic parameters were calculated from their general equations. The free energy activation of viscous flow $\left(\Delta \mathrm{G}_{\mathrm{v}}\right)$ of poly metal chelates was varied from 13.21-14.46 g/dL at different concentrations.

\section{REFERENCES}

1. C.-C. Kwok, S.-C. Yu, I.H.T. Sham and C.-M. Che, Chem. Commun., 2758 (2004).

2. M.A.A. Akl, I.M.M. Kenawy and R.R. Lasheen, Microchem. J., 78 , 143 (2004).
3. Z.H. Xie, F.Z. Xie, L.Q. Guo, X.C. Lin and G.N. Chen, J. Sep. Sci., 28, 462 (2005).

4. E.A. Moawed, M.A.A. Zaid and M.F. El-Shahat, Acta Chromatogr., 15, 220 (2005).

5. M.A. Hamed, K.S. Abou- El-Sherbini and H. R. Lotfy, J. Chin. Chem. Soc., 53, 605 (2006).

6. S. Çavus and G. Gürdag, Polym. Adv. Technol., 19, 1209 (2008).

7. C. Noureddine, A. Lekhmici, Q. Ali, M. Ruba, M. Zalloum and S. Mubarak, J. Macromol. Sci. Part A, 47,177 (2010).

8. M.Y. Khuhawar, A. Shah and M.A. Mughal, Chin. J. Polym. Sci., 25, 399 (2007).

9. M. Tunçel, A. Özbülbül and S. Serifin, React. Funct. Polym., 68, 292 (2008).

10. Z. Rezvani, K. Nejati, E. Alizadeh and R. Sammimi, J. Mol. Cryst. Liq., 533, 16 (2010).

11. G. Aysegul, T. Mehmet, D. Havva and R. Alan Wheatley, Inorg. Chim. Acta, 358, 1785 (2005).

12. M.Y. Khuhawar and A.H. Channar, J. Macromol. Sci. A, 32, 523 (1995).

13. M.Y. Khuhawar, M.A. Mughal and A.H. Channar, Eur. Polym. J., 40, 805 (2004).

14. A. Shah and A.A. Shah, Asian J. Chem., 25, 4215 (2013).

15. Ö. Saatçilar, N. Satiroglu, S. Bektas, Ö. Genç and A. Denizli, React. Funct. Polym., 50, 41 (2002).

16. V.N.R. Pillai and A. Mohan, in ed.: K.S.V. Srinivasan, Macromolecules New Frontiers, Allied Publishers Ltd., vol. II, p. 433 (1998).

17. H. Mart and R. Adalet, Polym. Degrad. Stab., 83, 255 (2004).

18. M.E. El-Sayed Mansour, A. A. Kaseem, H. Nourel-Din and A. A. ElToukhy, Macromol. Rep., 28, 103 (1991).

19. A. Shah and A.A. Shah, Asian J. Chem., 25, 7513 (2013). 